\title{
A salute to, new to me, Nutrafoods readers
}

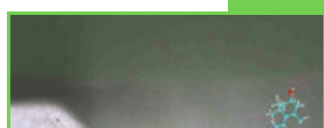

Francesco Di Pierro

Correspondence to:

Francesco Di Pierro

f.dipierro@vellejaresearch.com

(C) Springer - CEC Editore 2015

Dear esteemed reader, starting with this issue, as Editor-in-Chief, I assume with honour the task of taking Nutrafoods on a new, and hopefully long, adventure. Like any other adventure, it will be full of challenges and, unfortunately, the possibility of making mistakes. However, also like any other adventure, it will certainly include fun and satisfaction.

Being Editor-in-Chief of Nutrafoods means primarily dealing with the science of nutraceuticals. These tools are now consolidated in the hands of researchers, nutritionists and physicians, and their use has proven to be advantageous, when the result of smart and appropriate choices, for users' health. Despite this, there is always a huge need for further scientific studies, especially with regard to aspects of research and development of herbal ingredients and probiotics. While working with amino acids, vitamins, minerals and real food marketed as "nutraceuticals" may appear relatively simple, the same cannot be said of herbal nutraceuticals and probiotics.

For the first, herbal nutraceuticals, there are still obvious problems: (1) the incorrect chemical characterisation (problems ranging from real in toto standardisation of the product to its titration in relation to what is considered to be an "active" fraction or simply a fraction "marker") situation that inevitably leads to poor repeatability and/or to poor overlap of preparations identified with the same nomenclature; and (2) the problem of the poor oral absorption, typical of most herbal remedies, which leads to poor knowledge of the pharmacokinetics and pharmacodynamics of many herbal preparations.

For the latter, probiotics, there are obvious problems related to: (1) low stability in the finite forms; (2) modest phenotypic and genotypic typing concerning the strains used; and (3) a poor understanding of how much a failure in colonisation is actually a harbinger of the absence of measurable health effect. In this sense, Nutrafoods will make every effort to point out, whenever the situation so requires, the need to raise the profile of science of nutraceuticals. Being Editor-in-Chief of Nutrafoods also means trying to implement new publishing proposals; I applaud those who have preceded me-what they have already done is of obvious value. In future issues, there will be new features (commentary, letters, etc.) that I hope Nutrafoods readers will find useful. Finally, being Editor-in-Chief of Nutrafoods means trying to raise discussions on topics, which at least theoretically should be of interest to most readers, with the aim of creating scientific debates. These "provocations" will be published as editorials in each issue.

So, let's start with the first one in an attempt to raise debate on the following topic: Is there a logical application for nutraceuticals in the global scientific world's fight against antibiotic resistance? 